\title{
THE MALE OF THE PARTHENOGENETIC MAY-FLY, AMELETUS LUDENS.
}

\author{
By James G. Nefenham. \\ Cornell University, Ithaca, N. Y.
}

This paper is to record the capture of a single adılt male specimen of Ameletus ludens and to describe it. This sex has been sought diligently for more than a dozen years by a number of competent students of the Ephemerida, and many hundreds of nymphs have been reared in a vain effort to obtain it. Females are common enough at Ithaca, N. Y. The nymphs live in the pools of the rapid brooks that run down East Hill into Cayuga Lake. They poise gracefully on submerged twigs, or dart rapidly about over the sandy bottom, and are easily collected in April and May. Dr. W. A. Clemens found a single male sub-imago and took it into the laboratory but it died before its final moulting (Canad. Ent. 54: 77-78, 1922). On June 9, 1924, Dr. O. A. Johannsen captured a single adult male in flight by the side of Vanishing Brook near his home on Cornell Heights, and turned it over to me for study.

The nymph of this species was briefly described and beautifully figured by Eaton in his Monograph (Trans. Linn. Soc. Lond. (2) 3: 204, pl. 49) in 1885: it was doubtfully (and, as we now know, incorrectly) referred to the genus Chirotenetes, whose nymph was then unknown. The specimen had been collected in 1874 by Mr. Hubbard at Trenton Falls, N. Y. Female subimagos taken by Mr. D. B. Young in transformation at Newport, N. Y. were described by me in 1905 (N. Y. State Mus. Bull. 86: 36$)$.

Males of the other species of Ameletus, all of which come from the Rocky Mountains or farther westward, are well known. The search for the male of this species was begun by Miss Anna H. Morgan. In 1911 she described the adult female (Ann. Ent. Soc. Amer. 4: 118) and gave a detailed report of rearings of scores of nymphs taken at Ithaca, N. Y., all of which were females. She first pointed out that here is a case of probable parthenogenesis. Two years later she described and figured the 
curiously sculptured egg (Ann. Ent. Soc. Amer. 6: 400, Pl. 52, fig. 59, 1913); and she continued to rear the nymphs without finding a single male. I have myself, also, reared scores of nymphs-all females. Clemens examined hundreds of nymphs and found them all females. He demonstrated parthenogenesis by taking the eggs of these females, reared in isolation from males and unmated, and hatching them. He found the period of incubation to be five months (1. c., p. 78).

I have recently come upon this same marked tendency toward parthogenesis in the genus Ephemerella. In the course of a biological survey of the Lloyd-Cornell Reservation near McLean, N. Y., made during the past summer, two species of this genus were collected, and the commoner one was represented only by females. Hundreds of nymphs were collected by Mr. C. K. Sibley and myself, and scores of these were reared in cages, and only females were found. As a nymph this species has long been known. I described and figured it in 1905 (as Ephemerella $s p$. N. Y. State Museum Bull. 86:45, Pl. 10). It is widely distributed in New York State. Since no males are to be had and there is no present prospect of obtaining materials for more adequately characterizing the species, it might as well bear a name, so I propose the name Ephemerella feminina for it. I note that Dodds, in describing a similar Ephemerella nymph from Colorado (Trans. Amer. Ent. Soc. 49:99, 1923), says of it "About thirty nymphs of this species in our collection include no males."

Little is known as yet concerning unusual life cycles in the Ephemerida. The ovo-viviparous habit of the European Chloeon dipterum has long been known (See Lestage, Larves aquatiques des Insectes d'Europe, Vol. I, p. 250, 1921). Recently Miss Helen E. Murphy, on dissecting out the eggs from the ovaries of a female of a South American Callibætis, discovered them to contain well grown embryos; wherefore, we named this new species Callibretis viviparus (Lloyd Library Bull. 24: 50, Pl. XII, fig. 154, 1924). It is probable than much remains to be discovered on more complete studies of the life histories of the group.

Cytologists who gather females of Ameletus ludens for the study of chromosome behavior in development need to be re- 
minded that it is not necessarily and exclusively parthenogenetic. The male may be described as follows:-

\section{Ameletus ludens Needham.}

Adult male: Length of body $8.5 \mathrm{~mm}$; tails $10.5 \mathrm{~mm}$. additional; fore wing $9 \mathrm{~mm}$; fore leg $12 \mathrm{~mm}$.

Head blackish, including the small lower division of the compound eyes. The large subspherical upper division of the eyes is honey yellow. Antennæ black.

The dorsum of the thorax is brown, with only small peripheral yellow markings around the humeri and on the metanotum. On the latter a pair of divergent pale marks is followed by a yellow U-mark in the rear upon the crest. In a side view the dorsum shines by reflected light with a golden metallic lustre. The thorax is black beneath except for narrow areas around the leg bases. The abdomen is brownish above, varied with paler on the middle segments at the ends. Beneath, the abdomen is whitish on the basal half. Middle and hind legs are brown; the fore legs, blackish, with one claw somewhat paler. Wings hyaline, with all venation black except at the extreme base. Tails blackish, becoming a little paler apically. Forceps black, tawny at the base, with extremely short basal segment, subequal terminal segments and the second segment much exceeding in length the other three taken together.

This is the smallest known species of the genus. Its nearest allied species is Ameletus velox Dodds (Trans. Amer. Ent. Soc. 49: 105, Pl. 8, fig. 17, 1923). The male genitalia differ from those of that species in the following points: the basal segment of the forceps is much shorter, being wider than long; the second segment is less cylindric, being constricted at its basal third and widened toward both ends; between the two triangular lobes of the plate beneath the penes there is a broadly rounded median notch; and the penes themselves are shorter and less incurved at the tips.

The unique male specimen is in the Cornell University collection. 

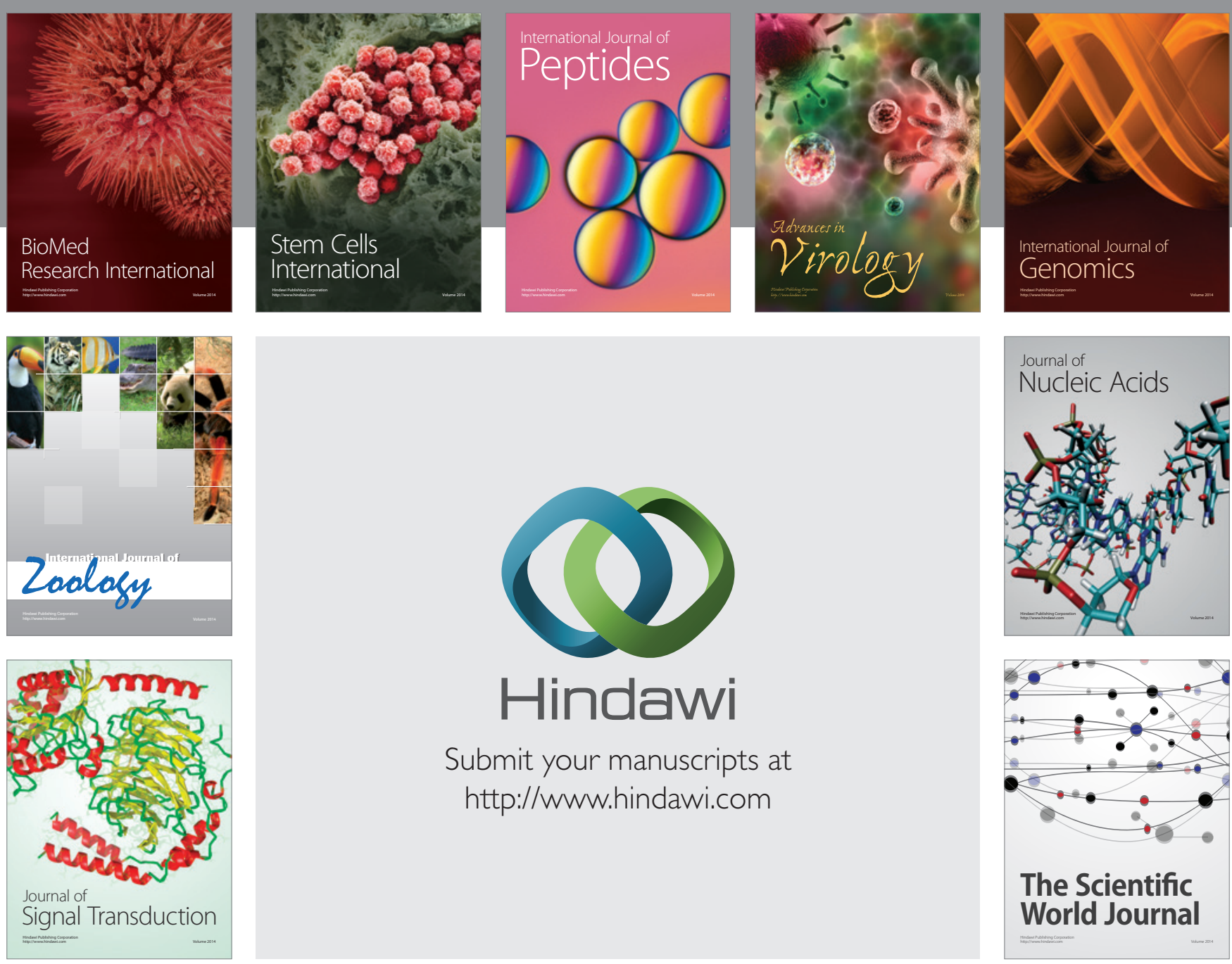

Submit your manuscripts at

http://www.hindawi.com
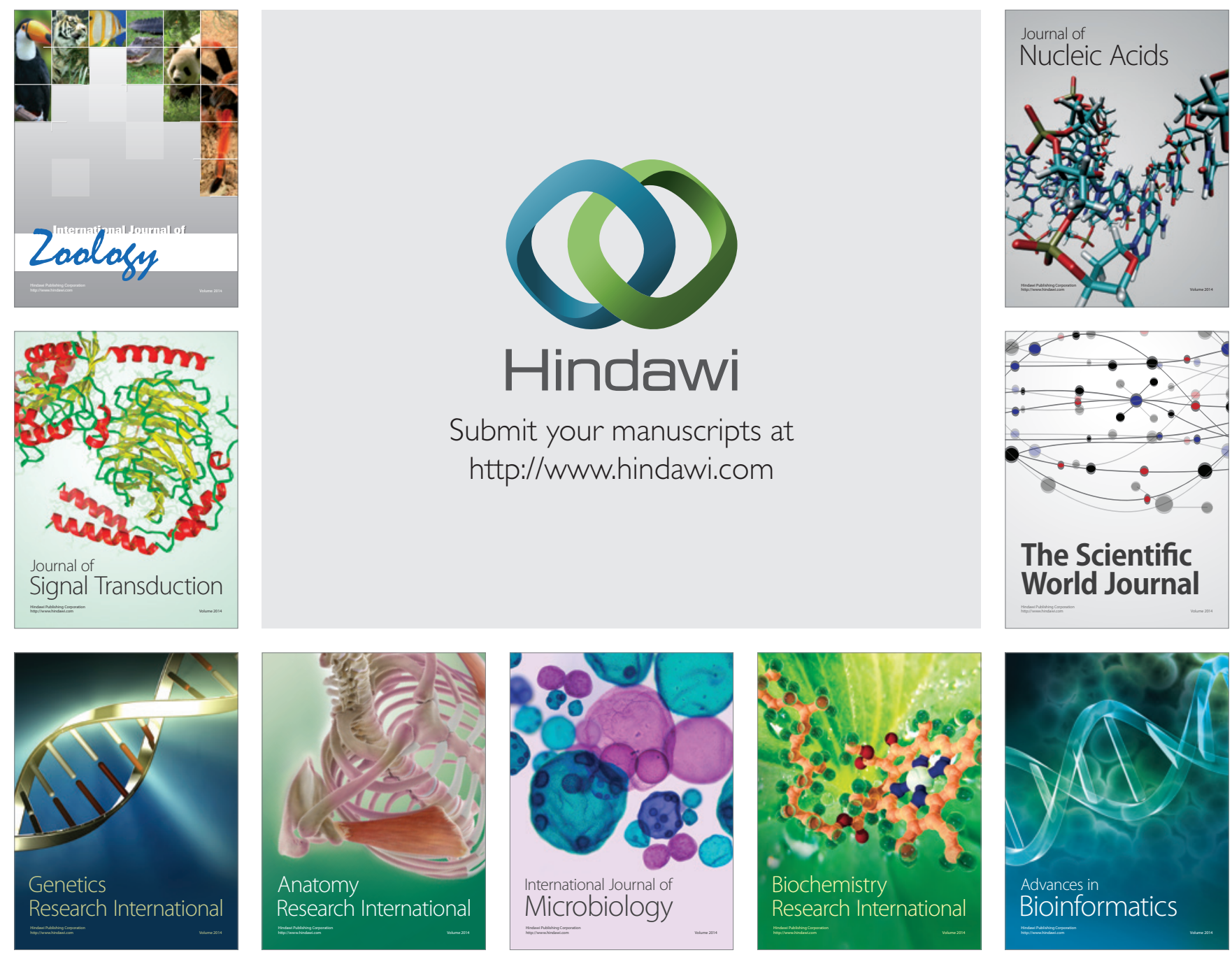

The Scientific World Journal
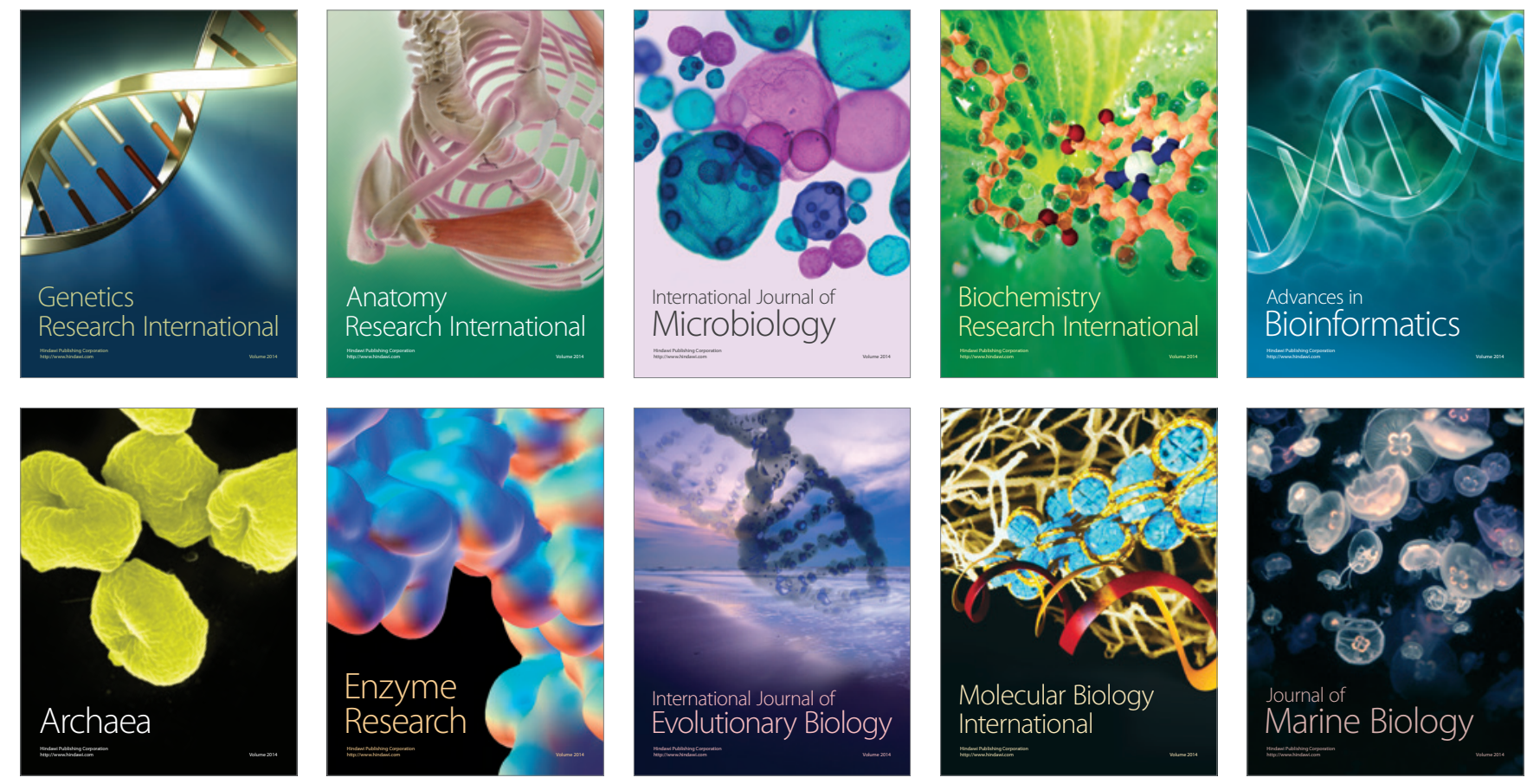